\title{
The $\mathrm{Fe}$ (III) and $\mathrm{Ga}$ (III) coordination chemistry of 3-(1- hydroxymethylidene) and 3-(1-hydroxydecylidene)-5-(2- hydroxyethyl)pyrrolidine-2,4-dione: Novel tetramic acid degradation products of homoserine lactone bacterial quorum sensing molecules
}

\author{
Ariel A. Romano ${ }^{a}$, Tobias Hahn ${ }^{a}$, Nicole Davis ${ }^{a}$, Colin A. Lowery ${ }^{b}$, Anjali K. Struss ${ }^{b}$, Kim D. \\ Janda $^{b}$, Lars H. Böttgerc, Berthold F. Matzanke ${ }^{c}$, and Carl J. Carrano ${ }^{a,}{ }^{*}$ \\ aDepartment of Chemistry and Biochemistry, San Diego State University, San Diego, CA \\ 92182-1030 \\ bThe Skaggs Institute for Chemical Biology and Departments of Chemistry and Immunology \& \\ Microbial Science, The Scripps Research Institute, Worm Institute for Research and Medicine \\ (WIRM), The Scripps Research Institute, La Jolla, CA 92037 \\ Isotopen Laboratorium, Sektion Naturwissenschaften, Universität zu Lübeck, Lübeck, Germany \\ D-23528
}

\begin{abstract}
Bacteria use small diffusible molecules to exchange information in a process called quorum sensing (QS). An important class of quorum sensing molecules used by Gram-negative bacteria is the family of $N$-acylhomoserine lactones (HSL). It was recently discovered that a degradation product of the QS molecule 3-oxo- $\mathrm{C}_{12}$-homoserine lactone, the tetramic acid 3-(1-

hydroxydecylidene)-5-(2-hydroxyethyl)pyrrolidine-2,4-dione, is a potent antibacterial agent, thus implying roles for QS outside of simply communication. Because these tetramic acids also appear to bind iron with appreciable affinity it was suggested that metal binding might contribute to their biological activity. Here, using a variety of spectroscopic tools, we describe the coordination chemistry of both the methylidene and decylidene tetramic acid derivatives with $\mathrm{Fe}(\mathrm{III})$ and $\mathrm{Ga}(\mathrm{III})$ and discuss the potential biological significance of such metal binding.
\end{abstract}

Keywords

Quorum sensing; tetramic acid; iron binding; Mössbauer spectroscopy

\section{Introduction}

The ability of a population of unicellular bacteria to communicate with one another has enabled bacterial populations to act in a manner similar to multicellular organisms. This

@ 2011 Elsevier Inc. All rights reserved.
*Corresponding auther: C.J. Carrano, carrano@ sciences.sdsu.edu, Phone: 619-594-5929, Fax: 619-594-4634.

Publisher's Disclaimer: This is a PDF file of an unedited manuscript that has been accepted for publication. As a service to our customers we are providing this early version of the manuscript. The manuscript will undergo copyediting, typesetting, and review of the resulting proof before it is published in its final citable form. Please note that during the production process errors may be discovered which could affect the content, and all legal disclaimers that apply to the journal pertain. 
process, known as quorum sensing (QS), is mediated by the intercellular exchange of small, diffusible chemical signals called autoinducers [1-3]. These chemical signals have traditionally been classified according to structural similarities and the Gram classification of bacteria that respond to them. For example, Gram negative bacteria use $N$ acylhomoserine lactones (AHLs), whereas Gram-positive bacteria produce and respond to oligopeptides. As bacterial population density increases, the concentration of these autoinducers increases accordingly. Thus, upon reaching a threshold autoinducer concentration, bacteria coordinate gene expression and behave as a unified group. While this phenomenon is beneficial for the bacterial population, it often comes at the expense of human well-being, as QS regulates such processes as iron uptake, swarming, biofilm formation, and the production of virulence factors [5-7].

AHL-mediated QS is particularly important in the pathogenesis of the important human pathogen Pseudomonas aeruginosa, which possess a complex QS system. Two AHLs, $N$-3oxododecaonyl homoserine lactone (3-oxo- $\mathrm{C}_{12}$-HSL) and $\mathrm{N}$-butrylhomoserine lactone $\left(\mathrm{C}_{4}\right.$ HSL), figure 1, play significant roles in the QS of P. aeruginosa [3]. The action of these signals regulates genes responsible for encoding enzymes such as elastases A and B, catalase, and superoxide dismutase as well as controlling biofilm formation and the production of other virulence factors [8]. P. aeruginosa is an opportunistic pathogen in humans, and is the most common Gram-negative bacterium associated with hospitalacquired infections [9]. Particularly notorious is the role of $P$. aeruginosa in infections of the lungs of cystic fibrosis patients, where lung defense systems are severely impaired [10]. After initial lung colonization, $P$. aeruginosa forms biofilms and, once formed, these biofilms are rarely cleared from the lungs of CF patients and the patients often succumb to the infection [11]. P. aeruginosa infections are also problematic in immunocompromised patients suffering from diseases such as AIDS and neurotropic cancer, as well as burn victims [12-14]. Regrettably, the increasing prevalence of antibiotic resistance in $P$. aeruginosa further exacerbates these problems [15].

Emerging research has demonstrated that QS not only assists $P$. aeruginosa in establishing infections by allowing for communication, but the QS signals themselves exert deleterious effects on mammalian cells. For example, 3 -oxo- $\mathrm{C}_{12}$-HSL affects the innate immune response via modulation of the transcriptional activity of the central regulator of gene expression in the innate immune system, NF- $\mathrm{kB}$ [16-19]. Furthermore, 3-oxo- $\mathrm{C}_{12}$-HSL has also been demonstrated to induce apoptosis in human breast cancer cells [20], macrophages, and neutrophils [21]. Recently one of us (KDJ) demonstrated that $N$-(3-oxododecanoyl) homoserine lactone performs a previously unrecognized role: The autoinducer itself and the corresponding tetramic acid degradation product (Fig. 2) derived from an unusual Claisenlike condensation reaction, also function as innate bactericidal agents to possibly provide a competitive advantage in mixed species environments [22,23]. The tetramic acid degradation product, 3-(1-hydroxydecylidene)-5-(2-hydroxyethyl)pyrrolidine-2,4-dione (C12-TA), also tightly binds essential metals such as iron, possibly providing a previously unrecognized primordial siderophore.

The competition for iron is particularly intense in the human body, where iron availability is limited by both solubility and host iron storage mechanisms [24,25]. As such, bacterial pathogens depend on siderophores (low molecular weight chelating agents with extraordinarily high affinity for Fe(III)) to obtain iron, and $P$. aeruginosa employs two such molecules: pyochelin and pyoverdin [24,25]. Thus, because of the capacity of C12-TA to bind iron, we hypothesized a role for C12-TA in the iron acquisition of $P$. aeruginosa.

While the tetramic acid ring system has been known since the early 1960's to be a key structural element in various natural products [9] and that the 3-acyl substituted rings 
provide metal binding capacity, the coordination chemistry of these species has been surprisingly little studied [27-29]. Probably the best studied system is the fungal metabolite, tenuazonic acid where the coordination chemistry with $\mathrm{Cu}(\mathrm{II}), \mathrm{Fe}(\mathrm{III}), \mathrm{Ni}$ (II) and $\mathrm{Mg}$ (II) has been partially explored and a crystal structure of the $\mathrm{Cu}(\mathrm{II})$ complex reported [30,31].

Here, using a variety of spectroscopic tools, we describe the coordination chemistry of the decylidene tetramic acid degradation product derived from 3 -oxo- $\mathrm{C}_{12}-\mathrm{HSL}$, as well as a methylidene analog, with $\mathrm{Fe}(\mathrm{III})$ and $\mathrm{Ga}$ (III) and discuss their potential biological significance.

\section{Materials and Methods}

\section{Potentiometric and Spectrophotometric Titrations}

Standard carbonate-free solutions of $\mathrm{KOH}$ were prepared from Baker "Dilut-It" ampoules using boiled, purified water (i.e., $18 \mathrm{M} \square$ resistance; MilliQ) and were stored under Ascarite ${ }^{\mathrm{TM}}$ scrubbed argon. Base solutions were standardized with KHP to the phenolpthalein end point. The absence of carbonate $(<2 \%)$ was confirmed by Gran's plots [32]. Iron solutions were purchased from Fluka $(\mathrm{FeCl} 3 \bullet 6 \mathrm{H} 2 \mathrm{O}$ in $4 \% \mathrm{HCl})$ and the exact iron concentration determined by EDTA titration with Variamine Blue as an indicator. Excess acid in the iron solution was determined by passing an aliquot through a well-washed sample of the acid form of AG 50W-X8 cation exchange resin (Bio-Rad) and titrating the liberated acid. The excess acid was the difference between the total acid and three times the known iron concentration. Spectrophotometric and potentiometric titrations were performed in a jacketed, titration vessel connected to a constant temperature water bath and held at $25.0(1)^{\circ} \mathrm{C}$. Ionic strength was fixed at $0.1 \mathrm{M}$ with $\mathrm{NaCl}$. Hydrogen ion concentration was measured using a Mettler-Toledo DL50 titrator connected to a Mettler-Toledo DG111-5C combination electrode which was standardized with a three buffer sequence and corrected (as needed) to read the negative log of the hydrogen ion concentration directly using dilute $\mathrm{HCl}$ solutions. Titrant was added to the cell, which was kept under a blanket of Ascarite ${ }^{\mathrm{TM}}$ scrubbed argon gas. Ligand protonation constants were determined from the nonlinear refinement of a) the potentiometric titration data using the program PKAS developed by Martell and Motekaitis [33] or b) by NMR titration at $400 \mathrm{MHz}$ in $\mathrm{D}_{2} \mathrm{O}$. For the NMR titrations the $\mathrm{pH}$ was adjusted using $\mathrm{NaOD}(2.0 \mathrm{M})$ as a titrant and meter readings in $\mathrm{D}_{2} \mathrm{O}$ were corrected by adding 0.44 to obtain values of $\mathrm{pD}$ [34]. NMR titration data were fitted to a single $\mathrm{pK}_{\mathrm{a}}$ equilibrium using SigmaPlot 10.0. Spectrophotometric titration data were analyzed via nonlinear least squares refinement using SigmaPlot 10.0.

\section{Physical Measurements}

Routine electrospray-ionization mass spectrometry (ESI-MS) was performed by direct injection on an Agilent LC/MSD Trap XCT Plus mass spectrometer. Isotope distribution patterns were simulated using the program IsoPro. NMR experiments (i.e., ${ }^{1} \mathrm{H},{ }^{13} \mathrm{C}, \mathrm{DEPT}$ ) were run at $30^{\circ} \mathrm{C}$ in $\mathrm{D}_{2} \mathrm{O}$ containing $0.03 \%$ DSS on either a Varian 400 or $600 \mathrm{MHz}$ NMR spectrometer using standard pulse sequences obtained from the $\mathrm{VnmrJ}^{\mathrm{TM}}$ software (v. 2.2c). UV-visible spectra were recorded using a Cary $50 \mathrm{UV}$-vis spectrophotometer under PC control using the Cary WinUV software. Cyclic voltammetric experiments were conducted using a BAS (Bioanalytical Systems Inc., West Lafayette, IN) Epsilon voltammetric analyzer. All experiments were done under argon at ambient temperature in solutions with $0.1 \mathrm{M} \mathrm{NaCl}$ as the supporting electrolyte. Cyclic voltammograms (CV) were obtained using a three-electrode system consisting of Pt working, platinum wire auxiliary, and SCE reference electrodes. Potentials are reported versus the $\mathrm{Ag} / \mathrm{AgCl}$ ( $\mathrm{KCl}$ saturated) couple ( $197 \mathrm{mV}$ vs NHE). Solution magnetic studies were carried out by the Evans method in 
Wilmad coaxial NMR tubes at $600 \mathrm{MHz}$ using water as a solvent and t-butyl alcohol as the internal standard.

For Mössbauer spectroscopy solutions were transferred into Delrin ${ }^{\circledR}$ sample holders, frozen in liquid nitrogen, and kept at this temperature until measurement except for overnight transport on dry ice. The Mössbauer spectra were recorded in the horizontal transmission geometry using a constant acceleration spectrometer operated in conjunction with a 512channel analyzer in the time-scale mode. The detector consisted of a proportional counter filled with argon-methane (9:1). The source was at room temperature and consisted of 1.4 $\mathrm{GBq}\left[{ }^{57} \mathrm{Co}\right]$ diffused in Rh foil (WissEl, Starnberg, Germany). The spectrometer was calibrated against $\alpha$-iron at room temperature (RT). For measurements at $77 \mathrm{~K}$, samples were placed in a continuous-flow cryostat (Oxford Instruments). For measurements at $4.3 \mathrm{~K}$ and 2K a helium bath cryostat (MD306, Oxford Instruments) was employed. Spectral data were transferred from the multi-channel analyzer to a PC for further analysis employing the Vinda program on an Excel $2003 \AA$ platform. Isomer shift $\delta$, quadrupole splitting $\Delta \mathrm{E}_{\mathrm{Q}}, \mathrm{B}_{\mathrm{hf}}$ and percentage of the total absorption area were obtained by least-squares fits of Lorentzian lines to the experimental spectra. All values are rounded to last given digit. The isomers shifts $(\delta)$, the quadrupole splitting $\left(\Delta \mathrm{E}_{\mathrm{Q}}\right)$, the hyperfine field $\left(\mathrm{B}_{\mathrm{hf}}\right)$ and the line width $(\Gamma)$ are given in $\mathrm{mm} \bullet \mathrm{s}^{-1}$. The low relaxation ${ }^{6} \mathrm{~S}_{5 / 2}$ system was simulated with a spin-Hamiltonian [35]. The relative area is given in parts per hundreds.

\section{Bacterial Growth}

Utilization of tetramic acid as an iron source was measured with liquid growth assays as follows. Samples were prepared in triplicate in Falcon tubes $(50 \mathrm{ml})$ containing $15 \mathrm{ml} \mathrm{M} 9-$ glycerol minimal medium ( $0.5 \%$ glycerol): $50 \mu \mathrm{M}$ of the appropriate complex, $500 \mu \mathrm{M} 2,2-$ bipyridine, and $0.2 \%$ DMSO. The tubes were inoculated to $\mathrm{OD}_{600} 0.02$ with an overnight culture of $P$. aeruginosa PAO6383 ( $\triangle p v d F, \triangle p c h B A$ ) grown in M9-glycerol medium. Cultures were incubated at $37^{\circ} \mathrm{C}$ with shaking at $250 \mathrm{rpm}$ and $\mathrm{OD}_{600}$ was recorded every 24 $\mathrm{h}$ for a period of $192 \mathrm{~h} \mathrm{[36].} \mathrm{Antibiotic} \mathrm{activity} \mathrm{of} \mathrm{the} \mathrm{free} \mathrm{tetramic} \mathrm{acid,} \mathrm{and} \mathrm{its} \mathrm{Ga(III)} \mathrm{and}$ $\mathrm{Fe}(\mathrm{III})$ analogs were measured against the Gram negative $P$. aeruginosa PAO1 and Gram positive S. aureus (ATCC25923) in liquid culture containing 100 $\mu \mathrm{M}$ of the appropriate complex as described previously [23].

C12-TA as an iron source for $P$. aeruginosa was also examined using agar growth assays as follows. Filter disks $(6 \mathrm{~mm})$ were sterilized via autoclave, loaded with $10 \mu \mathrm{l}$ of a solution of C12-TA $(500,250$, and 125 , and $62.5 \mu \mathrm{M}$ in methanol) or desferrioxamine $(50 \mu \mathrm{M}$ in water), and the filter disks were allowed to air-dry. M9-soft agar (0.6\% agar, $0.5 \%$ glycerol) was sterilized via autoclave and, upon cooling to $45^{\circ} \mathrm{C}, 2$,2-bipyridine was added to a final concentration of $500 \mu \mathrm{M}$. At this point, an overnight culture of PAO6383 grown in $4 \mathrm{ml} \mathrm{LB}$ medium was centrifuged, the cell pellet was washed $3 \times$ with M9-glycerol medium and subsequently resuspended in $4 \mathrm{ml} \mathrm{M9-glycerol} \mathrm{medium.} \mathrm{This} \mathrm{suspension} \mathrm{was} \mathrm{used} \mathrm{to}$ inoculate the M9-agar, at $45^{\circ} \mathrm{C}$ at a dilution of 1:100. The resulting liquid was poured into Petri dishes (15 mL/dish) and allowed to solidify at room temperature. Once the agar solidified, the filter disks were placed on the surface of the agar, and the plates were incubated at $37^{\circ} \mathrm{C}$ and growth zones were read after $48 \mathrm{~h}$ [37].

\section{Results}

Ligands

3-acyl or alkoxycarbonyl substituted tetramic acids such as $\mathbf{1}$ and $\mathbf{2}$ are expected to be relatively strong acids, the acidity of which are dependent on the nature of the substituent group [26]. Potentiometric titration of solutions of the $\mathrm{C} 4$ analog, $\mathbf{1}$ and the $\mathrm{C} 12$ analog, $\mathbf{2}$, 
involved single proton equilibria and gave estimated of $\mathrm{pK}_{\mathrm{a}}$ values of 2.5 and 5.0 respectively. These values were confirmed by NMR titration where plots of chemical shift vs. pH (fig. 3) could be fitted to single proton equilibria and yielded values of 2.57(3) for 1 and 5.10(3) for 2.

\section{Complexation with $\mathrm{Fe}(\mathrm{III})$}

Mixing a solution of either $\mathbf{1}$ or $\mathbf{2}$ with one of $\mathrm{Fe}(\mathrm{III})$ at low $\mathrm{pH}$ gives rise to relatively intensely red brown colored solutions reminiscent of those displayed by hydroxamate siderophores [38]. The iron complex of $\mathbf{1}$ and $\mathbf{2}$ at $\mathrm{pH}$ of $2.5 \mathrm{had}$ a $\lambda_{\max }$ near $450 \mathrm{~nm}$ with extinction coefficients between $3500-4000 \mathrm{M}^{-1} \mathrm{~cm}^{-1}$. The ca. $4000 \mathrm{M}^{-1} \mathrm{~cm}^{-1}$ extinction coefficients suggest that these spectra arise from $\mathrm{O} \rightarrow \mathrm{Fe}(\mathrm{III}) \mathrm{LMCT}$ transitions. The stoichiometry of the complexes produced at low $\mathrm{pH}$ (ca. 2.5) was determined by the method of continuous variations (fig. 4) and indicated that 3:1 (L:M) complexes were produced as expected for these potentially bidentate ligands. The 3:1 stoichiometry was further supported by ESI-MS analysis. The $\mathrm{C} 4$ complex showed the presence of both $\mathrm{Fe}(\mathrm{TA})_{2}{ }^{+}$and $\mathrm{Fe}(\mathrm{TA})_{3}$ species when examined at low $\mathrm{pH}$ in positive ion mode (Supplementary Material). The fraction of the latter species increased with increasing ligand to metal ratio. For the $\mathrm{C} 12$ ligand only the $\mathrm{Fe}(\mathrm{TA})_{3}$ species was observed indicative of its more complete formation at this $\mathrm{pH}$.

Optical spectral changes were observed when $80 \% \mathrm{MeOH} / \mathrm{H}_{2} \mathrm{O}$ solutions of the 3:1 complex were raised or lowered in $\mathrm{pH}$ indicative of the occurrence of metal complex protonation/ deprotonation equilibria. As the $\mathrm{pH}$ is lowered from 2.5 to $>1.0$ the absorbance at ca. 450 $\mathrm{nm}$ decreased. In both cases the change in absorbance as a function of $\mathrm{pH}$ could be fit to a single proton protonation equilibrium assigned to the reaction:

$$
\mathrm{Fe}(\mathrm{TA})_{3}+\mathrm{H}^{+} \leftrightarrow \mathrm{Fe}(\mathrm{TA})_{2}{ }^{+}+\mathrm{TAH}
$$

Increasing the $\mathrm{pH}$ range from ca. 2.5 to 9 caused a complete bleaching of the LMCT transition for both the $\mathrm{C} 4$ and $\mathrm{C} 12$ iron complexes, the $\mathrm{pH}$ dependence of which could be fit to a hydrolysis of the tris complex to initially yield a species that we assign to be either a spin coupled (vide infra) $\mu$-dihydroxy or $\mu$-oxobridged dimer or polymer:

$$
\mathrm{nFe}(\mathrm{TA})_{3}+\mathrm{nH}_{2} \mathrm{O} \leftrightarrow\left[\mathrm{Fe}_{\mathrm{n}}(\mathrm{TA})_{n+2}(\mathrm{OH})_{\mathrm{n}}\right]+\mathrm{nTAH}
$$

or

$$
\mathrm{nFe}(\mathrm{TA})_{3}+\mathrm{n}-1 \mathrm{H}_{2} \mathrm{O} \leftrightarrow\left[\left(\mathrm{Fe}_{2}(\mathrm{TA})_{2} \mathrm{O}\right)_{n}\right]+\mathrm{nTAH}
$$

Non-linear least squares fits of the combined high and low $\mathrm{pH}$ data sets (fig. 5) gave values for $\log \mathrm{K}_{1}$ and $\log \mathrm{K}_{2}$ of 4.4 and 7.92(10) for the $\mathrm{C} 12$ analog and 1.22(2) and 6.3(3) for the $\mathrm{C} 4$ complex respectively.

Cyclic voltammetry (fig. 6) in water at $\mathrm{pH} 2.5$ showed a quasireversible one electron Fe(III) to $\mathrm{Fe}(\mathrm{II})$ reduction wave at $-352 \mathrm{mv}$ vs. SCE for $\mathrm{Fe}(1)_{3}$ and -329 for $\mathrm{Fe}(2)_{3}$. Increasing the scan rate from $100 \mathrm{mv} / \mathrm{sec}$ to $1 \mathrm{~V} / \mathrm{sec}$ or increasing the TA/Fe ratio from 3:1 to 10:1 increased the reversibility of the cyclic voltammogram. 


\section{Mossbauer and magnetic data}

For paramagnetic metal ions in general, and Fe(III) in particular, magnetic susceptibility and Mossbauer spectroscopy can yield valuable insights into coordination chemistry. Solution magnetic susceptibility data reveals that at low $\mathrm{pH}$ the $\mathrm{Fe}(\mathrm{TA})_{3}$ complexes have the magnetic moment expected for a mononuclear high spin $\mathrm{d}^{5} \mathrm{Fe}$ (III) center with $\mu=6.0$ (2) $\mathrm{BM}$. However as the $\mathrm{pH}$ is raised the magnetic moment is seen to fall towards zero (i.e. diamagnetic) in manner paralleling the changes seen in the optical spectra over the same $\mathrm{pH}$ regime. We attribute this to the initial formation of a strongly spin coupled dimer (or higher order polymer). More details of this process could be gleaned from Mössbauer spectroscopy.

Samples for Mössbauer spectroscopy were prepared at $\mathrm{pH}$ 1.98, 3.05, 4.05, 5.80, 6.07 and 7.48. At $77 \mathrm{~K}$ the $\mathrm{pH} 1.98$ sample represents a relaxing ${ }^{6} \mathrm{~S}_{5 / 2}$ system. Comparison with the same sample at $4.3 \mathrm{~K}$ discloses temperature dependent spin lattice relaxation due to spinorbit and orbit-phonon coupling (figure 7). However there is still relaxation left at $4.3 \mathrm{~K}$. We attribute this to concentration dependent spin-spin relaxation caused by energy transfer of interacting spins via dipole or exchange coupling. This relaxation accounts for approximately $54 \%$ of the absorption area. The spin Hamiltonian simulation yields $\delta$ of 0.54 $\mathrm{mm} \cdot \mathrm{s}^{-1}, \Delta \mathrm{E}_{\mathrm{Q}}$ of $0.26 \mathrm{~mm} \cdot \mathrm{s}^{-1}, \Gamma$ of $0.49 \mathrm{~mm} \cdot \mathrm{s}^{-1}$, an almost isotropic hyperfine coupling tensor $\mathrm{A}_{\mathrm{xx}} / \mathrm{g}_{\mathrm{N}} \mu_{\mathrm{N}}, \mathrm{A}_{\mathrm{yy}} / \mathrm{g}_{\mathrm{N}} \mu_{\mathrm{N}}, \mathrm{A}_{\mathrm{zz}} / \mathrm{g}_{\mathrm{N}} \mu_{\mathrm{N}}$ of $-24.0,-24.4,-24.2 \mathrm{~T}$, a zero field splitting $\mathrm{D}=$ $22 \mathrm{~cm}^{-1}$, a rhombicity parameter $\mathrm{E} / \mathrm{D}=0.33$ and an asymmetry parameter $\eta$ of 1 . The Mössbauer analysis identifies the low $\mathrm{pH}$ sample as a ${ }^{6} \mathrm{~S}_{5 / 2}$ system consistent with the low $\mathrm{pH}$ susceptibility data and its formulation as mononuclear $\mathrm{Fe}(\mathrm{TA})_{3}$.

Measurements at 77K disclose growth of a doublet species with increasing $\mathrm{pH}$ in the center of the spectrum. Mössbauer least squares fit analysis reveals, however, that at least two doublet species are present at $\mathrm{pH}$ 7.48: component $\mathrm{A}\left(\delta=0.45 \mathrm{~mm} \bullet \mathrm{s}^{-1}, \Delta \mathrm{E}_{\mathrm{q}}=0.50 \mathrm{~mm} \bullet \mathrm{s}^{-1}\right.$, $\Gamma=0.38 \mathrm{~mm} \bullet \mathrm{s}^{-1}$, rel. area $\left.50 \%\right)$ and component $\mathrm{B}\left(\delta=0.46 \mathrm{~mm} \bullet \mathrm{s}^{-1}, \Delta \mathrm{E}_{\mathrm{Q}}=0.93 \mathrm{~mm} \bullet \mathrm{s}^{-1}\right.$, $\Gamma=0.41 \mathrm{~mm} \bullet \mathrm{s}^{-1}$, rel. area $50 \%$ ). At $4.3 \mathrm{~K}$, the two species split magnetically yielding the following parameters: $\delta_{\mathrm{A}}=0.48 \mathrm{~mm} \bullet \mathrm{s}^{-1}, \Delta \mathrm{E}_{\mathrm{Q}, \mathrm{A}}=0.0 \mathrm{~mm} \bullet \mathrm{s}^{-1}, \mathrm{~B}_{\mathrm{HF}, \mathrm{A}}=49.9 \mathrm{~T} ; \delta_{\mathrm{B}}=0.43$ $\mathrm{mm} \bullet \mathrm{s}^{-1}, \Delta \mathrm{E}_{\mathrm{Q}, \mathrm{B}}=0.0 \mathrm{~mm} \bullet \mathrm{s}^{-1}, \mathrm{~B}_{\mathrm{HF}, \mathrm{B}}=46.4 \mathrm{~T}$ ). The hyperfine fields observed at $4.3 \mathrm{~K}$ reflect the presence of at least two polymeric ferric oxo compounds. Therefore, a simple dimeric species can be excluded at high $\mathrm{pH}$. In the $\mathrm{pH}$ range 3.05 through 6.7 the presence of both the polymeric and monomeric ferric iron species displays an equilibrium which is shifted with increasing $\mathrm{pH}$ completely into polymeric species.

\section{Ga(III) Complexation and the Mode of Metal Ion Coordination}

Because of the various tautomeric equilibria (Fig. 8) associated with the TA structure the exact coordination mode of these ligands with iron was in doubt [39]. In solution, NMR would be the probe of choice but it is not amenable to paramagnetic Fe(III) complexes. Thus we have made use of the $\mathrm{Ga}$ (III) analogs. Gallium(III) is widely used as a structural probe for Fe(III) since it has approximately the same size and charge but is diamagnetic [21]. ESIMS confirms that $\mathrm{Ga}(\mathrm{III})$ also binds to the tetramic acids with the same $3: 1$ stoichiometry as Fe(III) (i.e., m/z of 622 and 624 amu for the $\mathrm{C} 4$ and 958 and 960 amu for the $\mathrm{C} 12$ the 3:2 ratio reflecting the relative abundance of ${ }^{69} \mathrm{Ga}$ and ${ }^{71} \mathrm{Ga}$ (figure 9). The ${ }^{13} \mathrm{C}$ NMR spectra of the $\mathrm{Ga}$ (III) complex of the $\mathrm{C} 4$ ligand display a number of changes with respect to the free ligand. Most revealing are the ca. 1.8-5.6 ppm coordination induced shifts (CIS) in the resonances for carbons 2, 3, 6 and 7 (Table 1) as compared to values of $0.2 \mathrm{ppm}$ or less for the remaining carbons. The magnitude of the shifts for the proposed coordinating groups are similar to those seen with other ligands such as siderophores [41] and indicates unequivocally that the ligand is bound to $\mathrm{Ga}(\mathrm{III})$ as shown in fig. 8a and inferentially the same for Fe(III). 


\section{Biological Effects}

With the interactions between TA and Fe(III) clearly delineated, a role for C12-TA in the iron acquisition of $P$. aeruginosa was envisaged. Towards this end, we examined the capacity of C12-TA to facilitate the growth of the siderophore-mutant $P$. aeruginosa strain PAO6383 ( $\Delta p v d F, \triangle p c h B A)$ under iron limiting conditions [36]. PAO6383 was grown in both M9-glycerol medium and agar containing $500 \mu \mathrm{M} 2,2^{\prime}$-bipyridine to create irondeficient conditions. In the case of the liquid culture experiments, M9-glycerol medium was supplemented with $50 \mu \mathrm{M} \mathrm{C12-TA}$, which did not exhibit significant growth restoration of PAO6383 after 6 days (data not shown). In a separate set of experiments, PAO6383 was grown on $0.6 \%$ agar plates containing $500 \mu \mathrm{M} 2,2$ '-bipyridine. Filter disks containing between 500 and $62.5 \mu \mathrm{M}$ C12-TA, as well as $50 \mu \mathrm{M}$ desferrioxamine mesylate salt, were placed on the agar. In this case, only desferrioxamine, a fungal siderophore that may be used by $P$. aeruginosa [42], was able to promote the growth of PAO6383. As such, these data indicate that $\mathrm{C} 12$-TA alone is not sufficient to provide $P$. aeruginos $a$ with the iron required for growth.

We also verified that the free C12-TA but not its $\mathrm{C} 4$ analog display bacteriostatic activity against the Gram positive organism S. aureus. Since Ga(III) complexes of some siderophores have been reported to have potent antibacterial activity [41], the possibility that the $\mathrm{Ga}$ (III) complex would show enhanced activity was also investigated. However examination of the activity of the $\mathrm{Fe}(\mathrm{III})$ and $\mathrm{Ga}(\mathrm{III})$ complexes against $S$. aureus showed little if any toxicity beyond that of the free tetramic acid, suggesting that metal complexation had no role to play in the bacteriostatic effect.

\section{Discussion}

Although tetramic acids are expected to be relatively strong acids, the two ligands we examined in detail (1 and $\mathbf{2}$ ) differ considerably in their relative acidity. The significantly greater acidity of $\mathbf{1}$ vs. $\mathbf{2}$ is likely the result of two factors, both of which arise from the extended alkyl chain of $\mathbf{2}$. For one, the addition of weakly electron-donating methylene groups serves to destabilize the anionic species and increase the $\mathrm{pK}_{\mathrm{a}}$ of $\mathbf{2}$. A more significant contribution likely arises from the hydrophobic nature of $\mathbf{2}$, which contributes to the increased $\mathrm{pK}_{\mathrm{a}}$ through the decreased solvation of the deprotonated species [43,44]. A final reasoning for this observation may be the result of aggregation and molecular association of the C12-TA in solution. Recent studies have demonstrated that fatty acids, which possess the structural characteristic aliphatic chain connected to an acidic head group similar to C12TA, exhibit increased $\mathrm{pK}_{\mathrm{a}}$ values when the carbon tail extends past $\mathrm{C}_{6}$. This observation is a result of the tighter intermolecular interactions via van der Waals forces, resulting in a closer proximity of both protonated and deprotonated species. As a result, the deprotonated species serve to stabilize the acid proton and increase the $\mathrm{pK}_{\mathrm{a}}$ of the solution $[45,46]$. Because of the structural similarities of C12-TA to fatty acids, this phenomenon likely contributes to the significant differences in $\mathrm{pK}_{\mathrm{a}}$ between $\mathrm{C} 4$ - and C12-TA.

As originally reported the tetramic acids produced as degradation products from QS HSL do indeed bind Fe(III) with appreciable affinity (table 2). However table 2 illustrates a number of important points. The first is that while the overall formation constants for $\mathrm{Fe}$ (III) complexation appear to be similar to those of known siderophores such as DFO and pyoverdin, because of the differing denticity and acidity of the ligands, they are not nearly as effective iron chelators at physiological $\mathrm{pH}$, as indicated by their $\mathrm{pM}$ values. Secondly, since these tetramic acids are relatively strong acids, particularly as compared as compared to the very weakly acidic behavior of most of the iron binding moieties prevalent in the siderophores, they do not suffer strong competition from protons making them relatively more effective at low $\mathrm{pH}$ than some siderophores. However, correspondingly, because of 
relatively facile hydrolysis they compete rather poorly with hydroxide ion and indeed at higher $\mathrm{pH}$ are expected (and observed) to be unstable with respect to precipitation of $\mathrm{Fe}(\mathrm{OH})_{3}$. Finally, three of these bidentate ligands are needed to satisfy the octahedral six coordinate structure preferred by Fe(III) as compared to a single, typically hexadentate, siderophore molecule. This leads to a third power dependence on iron binding with respect to ligand concentration for the former and thus they are only effective iron chelators at relatively high concentrations.

While these ligands can bind iron well under certain conditions it is important to note that the species present at near neutral and biologically relevant $\mathrm{pH}$ does not appear to be exclusively the expected $\mathrm{Fe}(\mathrm{TA})_{3}$ complex. Indeed in the case of the $\mathrm{C} 4$ ligand $\mathbf{1}$ only about $7 \%$ of the total iron is expected to be present as $\mathrm{Fe}(\mathrm{TA})_{3}$ at $\mathrm{pH} 7.4$ while for the $\mathrm{C} 12$ ligand the tris complex represents approximately $75 \%$ of the total. The other species we formulate as unstable $\mu$-dihydroxy or $\mu$-oxobridged dimeric or higher order polymeric species which ultimately yield solid $\mathrm{Fe}(\mathrm{OH})_{3}$. It is further worth noting that for many similar ligands there is often a correlation between the LMCT band maximum or $\mathrm{pM}$ values with redox potential. The measured values of - 352 and $-329 \mathrm{mv}$ for the iron complexes of $\mathbf{1}$ and $\mathbf{2}$ are within those expected based upon such previously published correlations [47]. These modestly low redox potentials also lie well within the range accessible to biological reductants and thus iron bound to these complexes could be readily released by a reductive type mechanism. However in total, the data presented here argues against any overt iron transport role for these molecules.

If iron transport is not the major biological role for these molecules, then what is? It has been demonstrated that iron serves as a signal for biofilm formation [48] and is required for swarming in $P$. aeruginosa [31, 32]. Given the link between these behaviors and quorum sensing, [5,7] coupled with the iron affinity of C12-TA and the fact that it is derived from a major autoinducer of $P$. aeruginosa, several plausible biological functions of C12-TA may be postulated. We have initiated studies to decipher the role of C12-TA in these processes, but a clear role for C12-TA has yet to be definitively assigned. Additionally, P. aeruginosa has been demonstrated to lyse $S$. aureus and gain access to its intracellular iron pools [35]. While C12-TA does not directly promote the growth of $P$. aeruginosa, it may also play a role in this process as C12-TA has been recently reported as an antibacterial that targets the membrane of S. aureus [23]. Thus, in light of the myriad roles of iron in the survival and pathogenesis of $P$. aeruginosa, the distinct biological function of TA-Fe complexes remains unresolved and is a subject of ongoing investigation in our laboratories.

\section{Acknowledgments}

The work of LHB and BFM was in part supported by DFG grant Ma916/20-1 and that of CJC by NOAA Grants \#NA04OAR4170038 and NA08OAR4170669, California Sea Grant College Program Project numbers R/CZ-198 and R/CONT-205 and NSF grant CHE-0924313. ANR was supported at SDSU by National Institutes of Health, MBRS grant \#2R25GM058906 and TH by a DAAD RISE fellowship. CAL, AKS, and KDJ were supported by National Institutes of Health, AI077644. We also thank Cornelia Reimmann for providing PAO6383.

\section{References}

1. De Kievit TR, Iglewski BH. Bacterial quorum sensing in pathogenic relationships. Infect Immun. 2000; 68:4839-4849. [PubMed: 10948095]

2. Waters CM, Bassler BL. Quorum sensing: cell-to-cell communication in bacteria. Annu Rev Cell Dev Biol. 2005; 21:319-346. [PubMed: 16212498]

3. Fuqua C, Greenberg EP. Listening in on bacteria: acyl-homoserine lactone signalling. Nat Rev Mol Cell Biol. 2002; 3:685-695. [PubMed: 12209128] 
4. Lyon GJ, Novick RP. Peptide signaling in Staphylococcus aureus and other Gram-positive bacteria. Peptides. 2004; 25:1389-1403. [PubMed: 15374643]

5. Davies DG, Parsek MR, Pearson JP, Iglewski BH, Costerton JW, Greenberg EP. The involvement of cell-to-cell signals in the development of a bacterial biofilm. Science. 1998; 280:295-298. [PubMed: 9535661]

6. Tang HB, DiMango E, Bryan R, Gambello M, Iglewski BH, Goldberg JB, Prince A. Contribution of specific Pseudomonas aeruginosa virulence factors to pathogenesis of pneumonia in a neonatal mouse model of infection. Infect Immun. 1996; 64:37-43. [PubMed: 8557368]

7. Kohler T, Curty LK, Barja F, van Delden C, Pechere JC. Swarming of Pseudomonas aeruginosa is dependent on cell-to-cell signaling and requires flagella and pili. J Bacteriol. 2000; 182:5990-5996. [PubMed: 11029417]

8. Smith RS, Iglewski BH. Pseudomonas aeruginosa quorum sensing as a potential antimicrobial target. J Clin Invest. 2003; 112:1460-1465. [PubMed: 14617745]

9. Page MG, Heim J. Prospects for the next anti-Pseudomonas drug. Curr Opin Pharmacol. 2009; 9:558-565. [PubMed: 19748829]

10. Wagner VE, Iglewski BH. P. aeruginosa Biofilms in CF Infection. Clin Rev Allergy Immunol. 2008; 35:124-134. [PubMed: 18509765]

11. Winstanley C, Fothergill JL. The role of quorum sensing in chronic cystic fibrosis Pseudomonas aeruginosa infections. FEMS Microbiol Lett. 2009; 290:1-9. [PubMed: 19016870]

12. Bendig JW, Kyle PW, Giangrande PL, Samson DM, Azadian BS. Two neutropenic patients with multiple resistant Pseudomonas aeruginosa septicaemia treated with ciprofloxacin. J R Soc Med. 1987; 80:316-317. [PubMed: 3112380]

13. Franzetti F, Cernuschi M, Esposito R, Moroni M. Pseudomonas infections in patients with AIDS and AIDS-related complex. J Intern Med. 1992; 231:437-443. [PubMed: 1588272]

14. Lyczak JB, Cannon CL, Pier GB. Establishment of Pseudomonas aeruginosa infection: lessons from a versatile opportunist. Microbes and infection / Institut Pasteur. 2000; 2:1051-1060. [PubMed: 10967285]

15. Breidenstein EB, de la Fuente-Nunez C, Hancock RE. Pseudomonas aeruginosa: all roads lead to resistance. Trends Microbiol. 2011

16. Jahoor A, Patel R, Bryan A, Do C, Krier J, Watters C, Wahli W, Li G, Williams SC, Rumbaugh KP. Peroxisome proliferator-activated receptors mediate host cell proinflammatory responses to Pseudomonas aeruginosa autoinducer. J Bacteriol. 2008; 190:4408-4415. [PubMed: 18178738]

17. Kravchenko VV, Kaufmann GF, Mathison JC, Scott DA, Katz AZ, Grauer DC, Lehmann M, Meijler MM, Janda KD, Ulevitch RJ. Modulation of gene expression via disruption of NF-kappaB signaling by a bacterial small molecule. Science. 2008; 321:259-263. [PubMed: 18566250]

18. Kravchenko VV, Kaufmann GF, Mathison JC, Scott DA, Katz AZ, Wood MR, Brogan AP, Lehmann M, Mee JM, Iwata K, Pan Q, Fearns C, Knaus UG, Meijler MM, Janda KD, Ulevitch RJ. $\mathrm{N}$-(3-oxo-acyl)homoserine lactones signal cell activation through a mechanism distinct from the canonical pathogen-associated molecular pattern recognition receptor pathways. J Biol Chem. 2006; 281:28822-28830. [PubMed: 16893899]

19. Rumbaugh KP, Colmer JA, Griswold JA, Hamood AN. The effects of infection of thermal injury by Pseudomonas aeruginosa PAO1 on the murine cytokine response. Cytokine. 2001; 16:160-168. [PubMed: 11792126]

20. Li L, Hooi D, Chhabra SR, Pritchard D, Shaw PE. Bacterial N-acylhomoserine lactone-induced apoptosis in breast carcinoma cells correlated with down-modulation of STAT3. Oncogene. 2004; 23:4894-4902. [PubMed: 15064716]

21. Tateda K, Ishii Y, Horikawa M, Matsumoto T, Miyairi S, Pechere JC, Standiford TJ, Ishiguro M, Yamaguchi K. The Pseudomonas aeruginosa autoinducer N-3-oxododecanoyl homoserine lactone accelerates apoptosis in macrophages and neutrophils. Infect Immun. 2003; 71:5785-5793. [PubMed: 14500500]

22. Kaufmann GF, Sartorio R, Lee SH, Rogers CJ, Meijler MM, Moss JA, Clapham B, Brogan AP, Dickerson TJ, Janda KD. Revisiting quorum sensing: Discovery of additional chemical and biological functions for 3-oxo-N-acylhomoserine lactones. Proc Natl Acad Sci U S A. 2005; 102:309-314. [PubMed: 15623555] 
23. Lowery CA, Park J, Gloeckner C, Meijler MM, Mueller RS, Boshoff HI, Ulrich RL, Barry CE 3rd, Bartlett DH, Kravchenko VV, Kaufmann GF, Janda KD. Defining the mode of action of tetramic acid antibacterials derived from Pseudomonas aeruginosa quorum sensing signals. J Am Chem Soc. 2009; 131:14473-14479. [PubMed: 19807189]

24. Andrews SC, Robinson AK, Rodriguez-Quinones F. Bacterial iron homeostasis. FEMS Microbiol Rev. 2003; 27:215-237. [PubMed: 12829269]

25. Ratledge C, Dover LG. Iron metabolism in pathogenic bacteria. Annu Rev Microbiol. 2000; 54:881-941. [PubMed: 11018148]

26. Royles BJL. Naturally Occuring Tetramic Acids: Structure, Isolation, and Synthesis. Chem. Rev. 1995; 95:1981-2001.

27. Athanasellis G, Igglessi-Markopoulou O, Markopoulou J. Tetramic and Tetronic Acids as Scaffolds in Bioinorganic and Bioorganic Chemistry. Bioinorganic Chemistry and Applications. 2010; 2010:1-11.

28. Foye WO, Lo JR. Metal-Binding Abilities of Antibacterial Heterocyclic Thiones. J. Pharm. Sci. 1972; 61:1209-1212. [PubMed: 5050368]

29. LeBrun MH, Nicolas L, Boutar M, Gaudemer F, Ranomenjanahary S, Gaudemer A. Relationships Between the Structure and the Phytotoxicity of the Fungal Toxin Tenuazonic Acid. Phytochem. 1988; 27:77-84.

30. Lebrun MH, Duvert P, Gaudemer F, Gaudemer A, Deballon C, Boucly P. Complexation of the Fungal metabolite Tenuazonic Acids with Copper (II), Iron (III), Nickel (II) and magnesium (II) Ions. J. Inorg. Biochem. 1985; 24:167-181. [PubMed: 4045446]

31. Dippenaar A, Holzapfel CW, Boeyens JCA. Crystal Structure of Copper bis(tenuazonate) monohydrate. J. Crystr. Mol. Struct. 1977; 7:189-197.

32. Gran G. Analyst. 1952; 77:661-670.

33. Martell, AE.; Motekaitis, RJ. The Determination and Use of Stability Constants. Wiley-VCH Inc.; New York: 1992.

34. Perrin, DD.; Dempsey, B. Buffers for pH and Metal Ion Control. Chapman and Hall; London: 1974.

35. Gunnlaugsson, HP. Vinda, plugin for the Microsoft Excel program, designed for the analysis of Mössbauer Spectra. http://users-phys.au.dk/hpg/vinda.htm

36. Michel L, Bachelard A, Reimmann C. Ferripyochelin uptake genes are involved in pyochelinmediated signalling in Pseudomonas aeruginosa. Microbiology. 2007; 153:1508-1518. [PubMed: 17464065]

37. Rabsch W, Winkelmann G. The Specificity of Bacterial Siderophore Receptors Probed by Bioassays. Biol Met. 1991; 4:244-250. [PubMed: 1663779]

38. Harris WR, Carrano CJ, Raymond KN. Coordination Chemistry of Microbial Iron Transport Compounds. 16. Isolation, Characterization, and Formation Constants of Ferric Aerobactin. J. Am. Chem. Soc. 1979; 101:2722-2727.

39. Nolte MJ, Steyn PS, Wessels PL. Structural Investigations of 3-Acylpyrrolidine-2,4-diones by Nuclear Magnetic Resonance Spectroscopy and X-ray Crystallography. J.C.S. Perkin I. 1980:1057-1065.

40. Zhang G, Amin SA, Küpper FC, Holt PD, Carrano CJ, Butler A. Ferric Stability Constants of Representative Marine Siderophores: Marinobactins, Aquachelins, and Petrobactin. Inorg. Chem. 2009; 48:11466-11473. [PubMed: 19902959]

41. Carrano CJ, Drechsel H, Kaiser D, Jung G, Matzanke B, Winkelmann G, Rochel N, AlbrechtGary AM. Coordination chemistry of the carboxylate type siderophore rhizoferrin: The iron(III) complex and its metal analogs. Inorganic Chemistry. 1996; 35:6429-6436. [PubMed: 11666790]

42. Llamas MA, Sparrius M, Kloet R, Jimenez CR, Vandenbroucke-Grauls C, Bitter W. The heterologous siderophores ferrioxamine $\mathrm{B}$ and ferrichrome activate signaling pathways in Pseudomonas aeruginosa. J Bacteriol. 2006; 188:1882-1891. [PubMed: 16484199]

43. Bowden K, Young RC. Transmission of Polar Effects .11. Polar and Steric Effects in Reactions of Arylaliphatic Carboxylic Acids. Can J Chemistry. 1969; 47:2775. \&.

44. Headley AD, Mcmurry ME, Starnes SD. Effects of Substituents on the Acidity of Acetic-Acids. J Org Chem. 1994; 59:1863-1866. 
45. Kanicky JR, Poniatowski AF, Mehta NR, Shah DO. Cooperativity among molecules at interfaces in relation to various technological processes: Effect of chain length on the $\mathrm{pK}(\mathrm{a})$ of fatty acid salt solutions. Langmuir. 2000; 16:172-177.

46. Kanicky JR, Shah DO. Effect of premicellar aggregation on the $\mathrm{pK}(\mathrm{a})$ of fatty acid soap solutions. Langmuir. 2003; 19:2034-2038.

47. Crumbliss AL, Harrington JM. Iron Sequestration by Small Molecules: Thermodynamic and Kinetic Studies of natural Siderophores and Synthetic Model Compounds. Adv. Inorg. Chem. 2009; 61:179-250.

48. Singh PK, Parsek MR, Greenberg EP, Welsh MJ. A component of innate immunity prevents bacterial biofilm development. Nature. 2002; 417:552-555. [PubMed: 12037568]

49. Deziel E, Lepine F, Milot S, Villemur R. rhlA is required for the production of a novel biosurfactant promoting swarming motility in Pseudomonas aeruginosa: 3-(3-

hydroxyalkanoyloxy)alkanoic acids (HAAs), the precursors of rhamnolipids. Microbiology. 2003; 149:2005-2013. [PubMed: 12904540]

50. Nadal Jimenez P, Koch G, Papaioannou E, Wahjudi M, Krzeslak J, Coenye T, Cool RH, Quax WJ. Role of PvdQ in Pseudomonas aeruginosa virulence under iron-limiting conditions. Microbiology. 2010; 156:49-59. [PubMed: 19778968]

51. Mashburn LM, Jett AM, Akins DR, Whiteley M. Staphylococcus aureus serves as an iron source for Pseudomonas aeruginosa during in vivo coculture. J Bacteriol. 2005; 187:554-566. [PubMed: 15629927] 


\section{Highlights}

- $\quad$ Tetramic acids formed as degradation products of some homoserine lactone quorum sensors

- $\quad$ These tetramic acids bind iron with significant affinity to produce $\mathrm{ML}_{3}$ complexes at low $\mathrm{pH}$ and high ligand concentrations

- $\quad$ The properties of the tetramic acids and their iron complexes depend on chain length

- $\quad$ Tetramic acids do not facilitate iron uptake in $P$. aeruginosa

- The biological significance of the iron binding ability of these molecules remains unclear 
<smiles>CCCC(=O)NC1CCOC1=O</smiles>

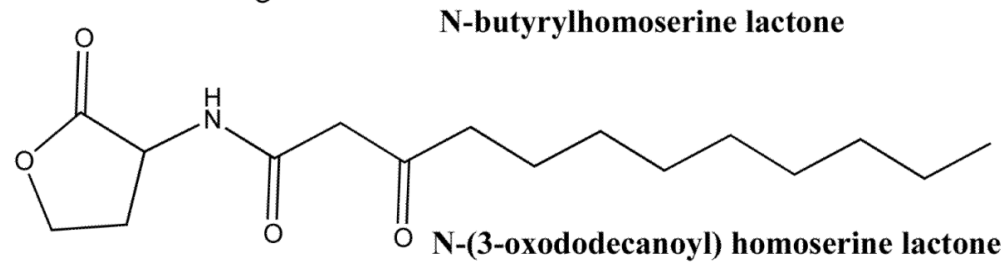

Figure 1.

Structures of two acylhomoserine lactone QS signals employed by $P$. aeruginosa: Nbutyrylhomoserine lactone (C4-HSL) and $\mathrm{N}$-(3-oxododecanoyl) homoserine lactone (3-oxo$\mathrm{C}_{12}$-HSL). 


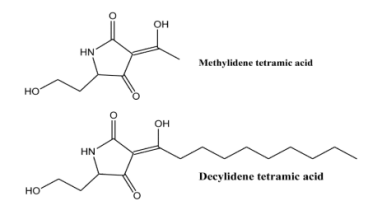

Figure 2.

Structures of methylidene tetramic acid (C4-TA, 1) and decylidene tetramic acid (C12-TA, 2), the tetramic acid degradation product of 3 -oxo- $\mathrm{C}_{12}$-HSL. 


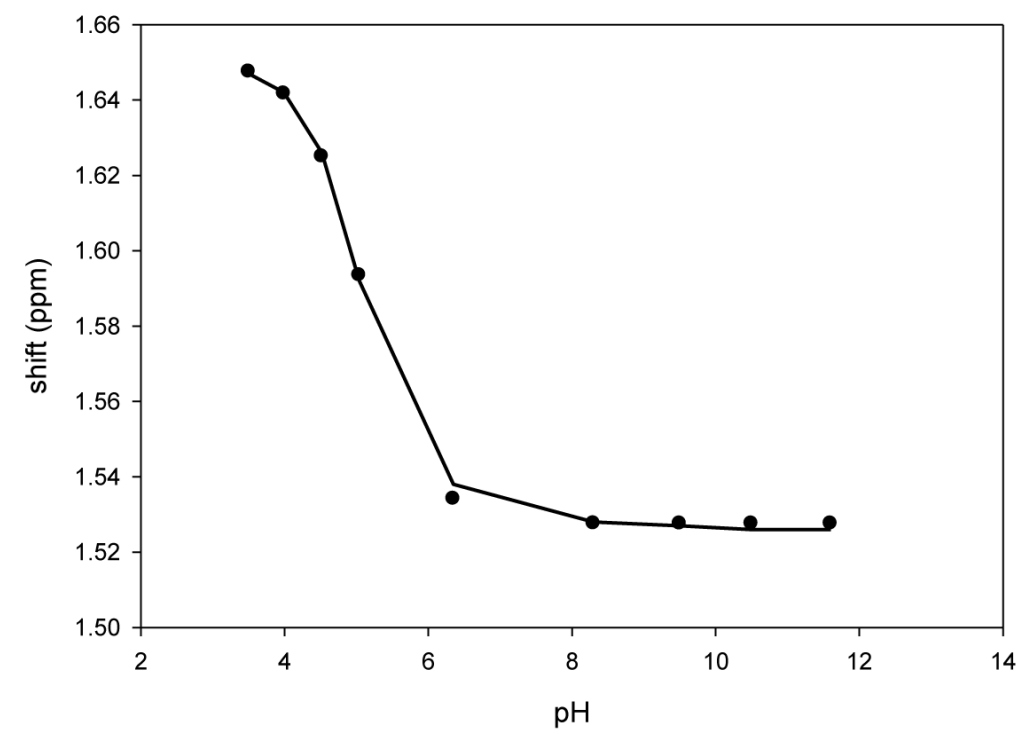

Figure 3.

Plot of chemical shift vs. $\mathrm{pH}$ for the NMR titration of 2 at $400 \mathrm{MHz}$ in $\mathrm{D}_{2} \mathrm{O}$. The solid line is a fit of the data to a single $\mathrm{pK}_{\mathrm{a}}$ equilibrium using SigmaPlot 10.0. 


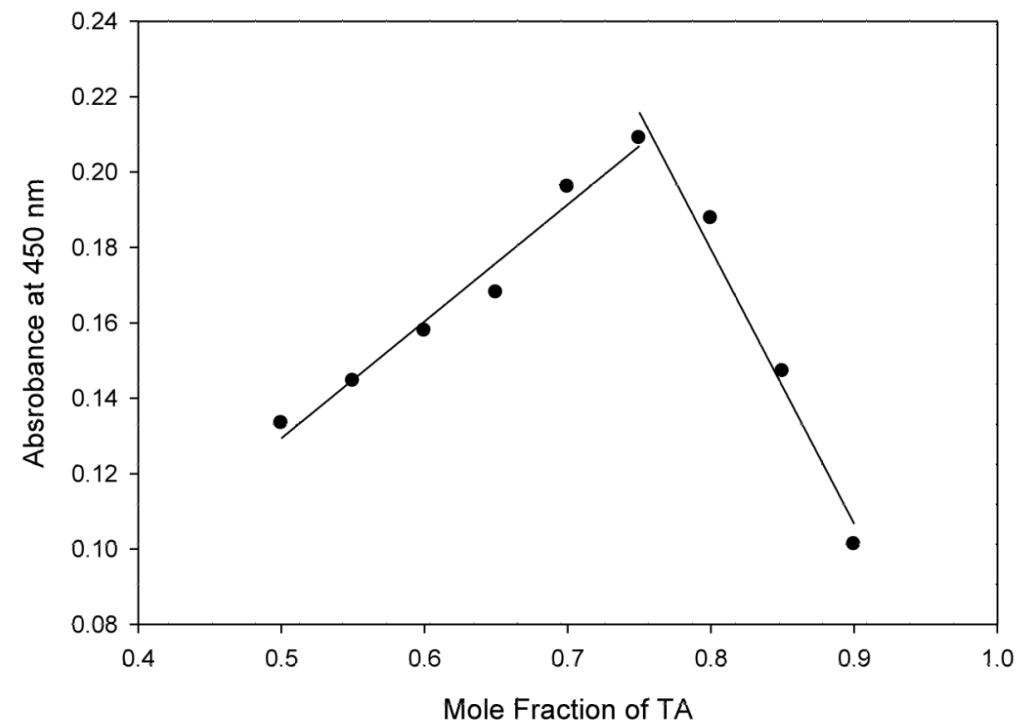

Figure 4.

A Job's method plot of absorbance at $450 \mathrm{~nm}$ vs. mole fraction of $\mathbf{1}$. 


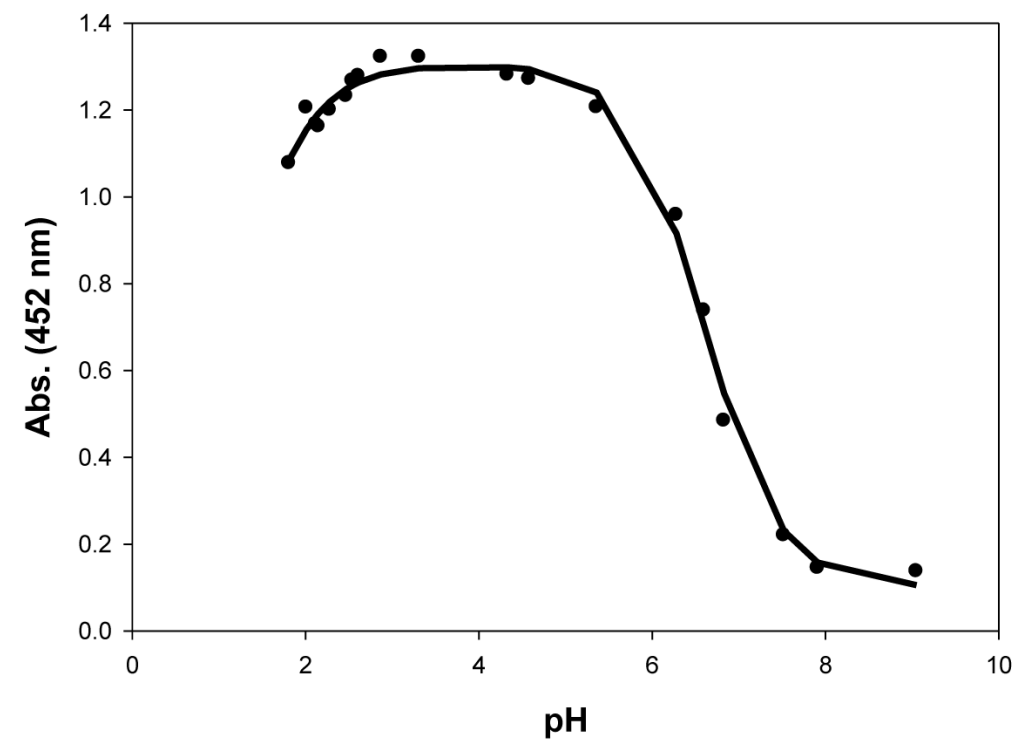

Figure 5.

Spectrophotometric titration of $\mathbf{1}$ in $80 \% \mathrm{MeOH} / \mathrm{H}_{2} \mathrm{O}$. The solid line is a fit to the data using a two $\mathrm{pK}_{\mathrm{a}}$ model. 


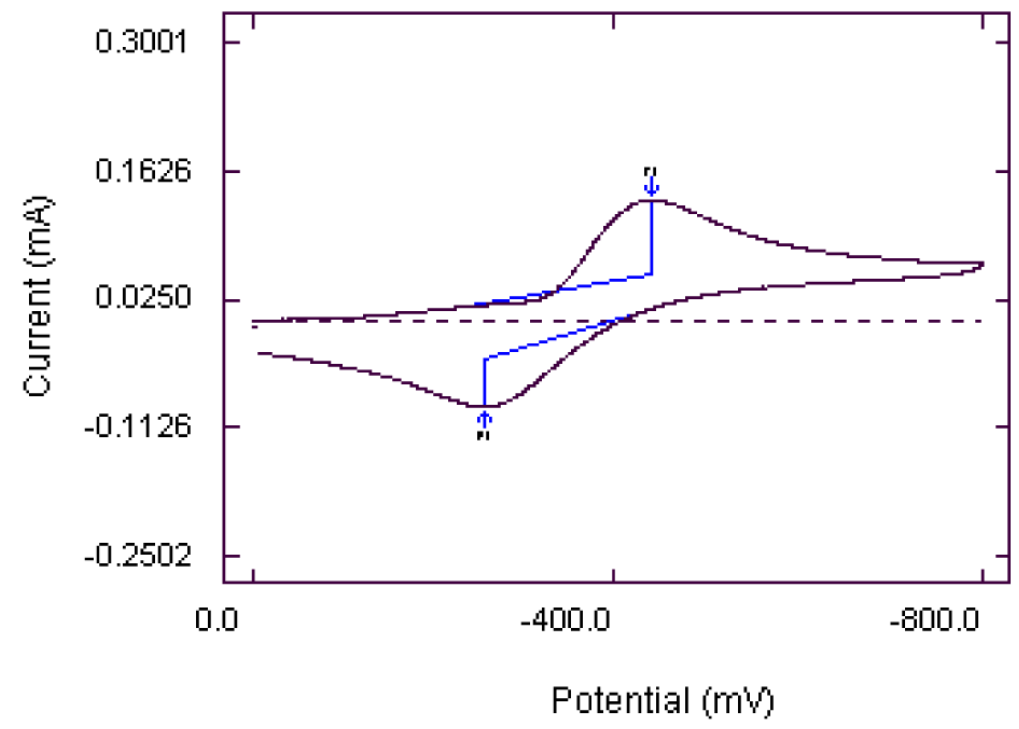

Figure 6.

Cyclic voltammogram (CV) of 1 at $200 \mathrm{mv} / \mathrm{sec}$ in aqueous solution containing $0.1 \mathrm{M} \mathrm{KNO}_{3}$ as a supporting electrolyte. Cyclic voltammogram was obtained using a three-electrode system consisting of a $\mathrm{Pt}$ disk working, platinum wire auxiliary, and $\mathrm{Ag} / \mathrm{AgCl}$ reference electrodes. IR compensation was applied before each CV was recorded. 

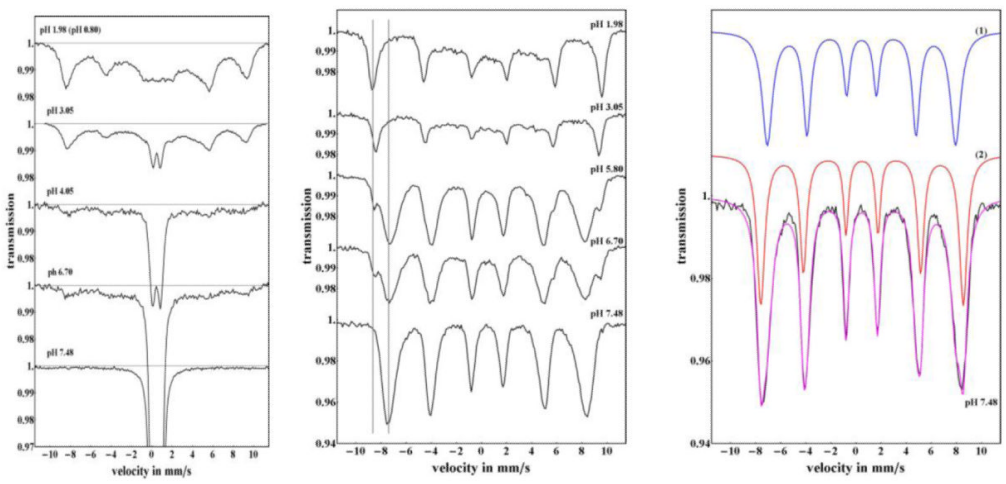

Figure 7.

comparison of Mössbauer spectra of $\mathbf{1}$ as a function of pH: left panel) 4.3K, center panel) $77 \mathrm{~K}$, and right panel) calculated subspectra and composite experimental spectrum at $\mathrm{pH}$ of 7.48 .

J Inorg Biochem. Author manuscript; available in PMC 2013 February 1. 

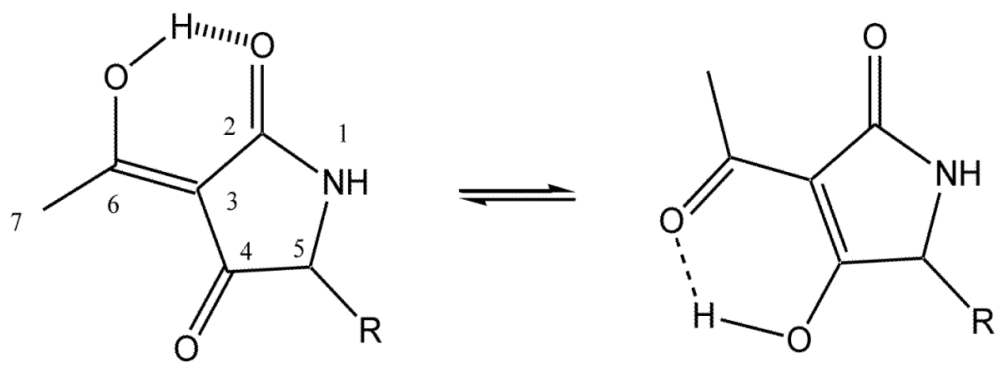

Figure 8.

Tautomeric equilibria in tetramic acids. 

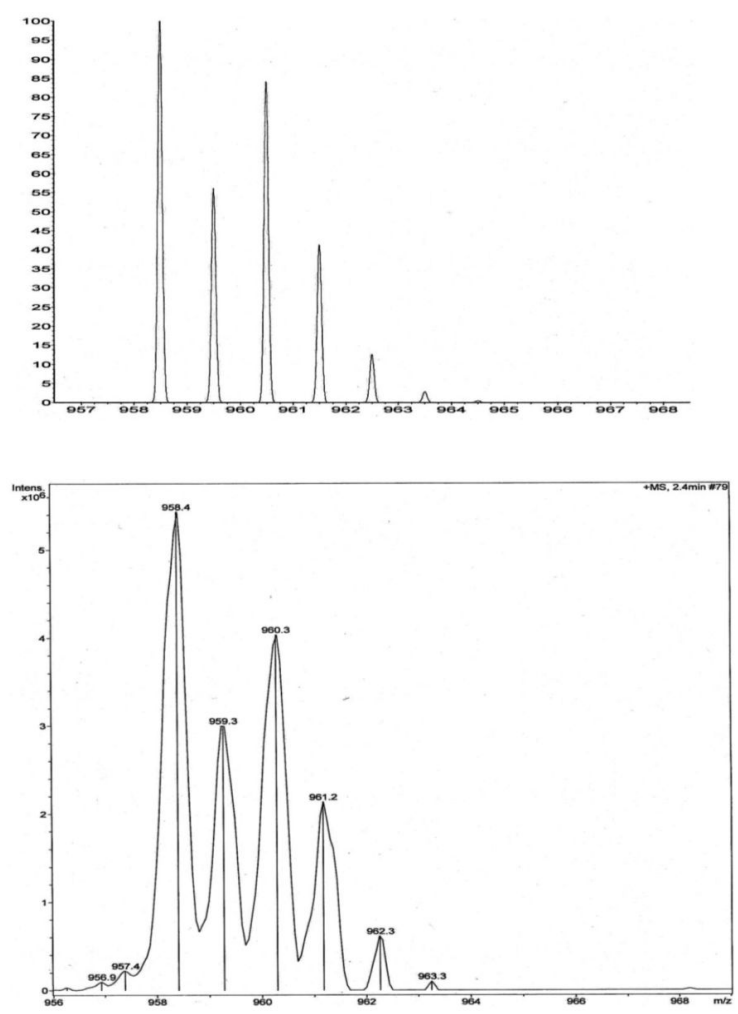

Figure 9.

Positive ion mode ESI-MS of the Ga(III) complex of 2. Upper) calculated isotope distribution pattern for $\mathrm{Ga}(2)_{3}$, lower) experimental isotope pattern, positive ion ESI-MS. 
Table 1

Coordination inducted Shifts in the 13C NMR spectra of 1 . Numbering is according to figure 8.

\begin{tabular}{|l|l|}
\hline C \# & CIS (ppm) \\
\hline 2 & +1.9 \\
\hline 3 & -1.8 \\
\hline 4 & -0.3 \\
\hline 5 & +0.14 \\
\hline 6 & +5.6 \\
\hline 7 & +3.6 \\
\hline 8 & -0.1 \\
\hline 9 & +0.86 \\
\hline
\end{tabular}




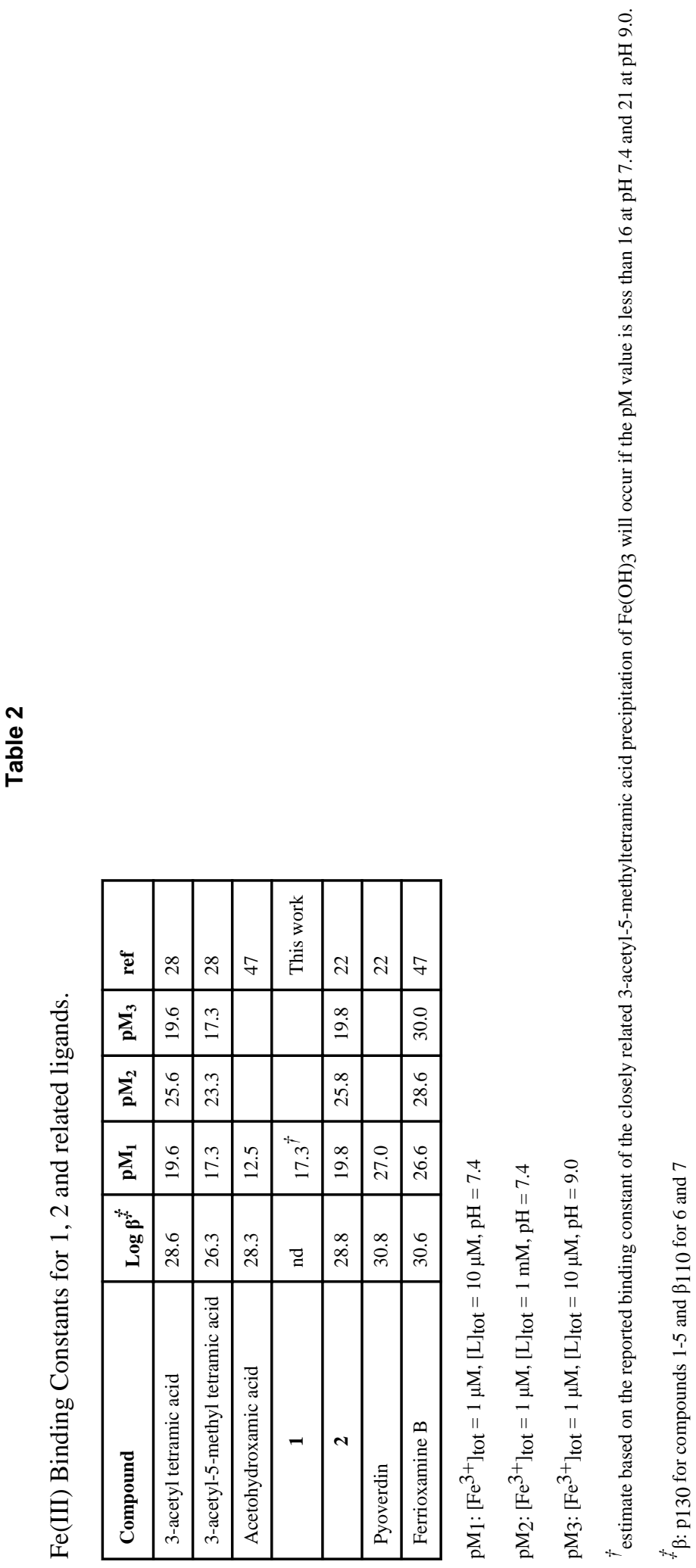

J Inorg Biochem. Author manuscript; available in PMC 2013 February 1. 